\title{
Cláusula de Abertura dos Direitos Fundamentais e Status Hierárquico dos Tratados Internacionais de Direitos Humanos
}

\author{
Juliane Andréa de Mendes Hey Melo \\ Mestre em Direito, na área de concentração em Direitos \\ Fundamentais e Democracia, pelo Centro Universitário \\ Autônomo do Brasil - Unibrasil, com período sanduíche \\ na Universidad Pablo de Olavide - Espanha. Professora \\ do Centro Universitário Curitiba - Unicuritiba. juliane@ \\ heymelo.com.br
}

\section{Ariadne da Silveira Bonato}

Mestre em Direito, na área de concentração em Direitos Fundamentais e Democracia, pelo Centro Universitário Autônomo do Brasil - Unibrasil, com período sanduíche na Universidad Pablo de Olavide - Espanha. ariadne. bonato@gmail.com

\section{Resumo:}

Este artigo visa a abordar e discutir sobre o diálogo entre a ordem interna e a ordem internacional na seara dos direitos humanos, de modo a proporcionar pequena contribuição à discussão sobre 0 tema. Analisa-se a abertura do texto constitucional realizada pelo artigo $5^{\circ}$, $\S 2 \circ$ da Constituição Federal, chegando ao viés do Estado Constitucional Cooperativo. Nesse sentido, investiga-se qual a influência do da inserção do § 3 do artigo 5 da Constituição Federal, em especial sobre o status hierárquico dos tratados de direitos humanos, bem como sua relação com 0 disposto no $\S 20$ do mesmo dispositivo.

Palavras-chave: Constituição. Direitos humanos. Cláusula de abertura. Tratados internacionais. Hierarquia. 


\title{
Opening Constitutional Clause of Fundamental Rights and Hierarchical Status of International Human Rights Treaties
}

\begin{abstract}
:
This article aims to investigate on the dialogue between the internal order and the international order in the harvest of human rights, to provide small contribution to the discussion on the topic. Analyzes the opening of the Constitution made by art. $5 \circ$, $\S 2 \circ$ of the Constitution, reaching the Cooperative Constitutional State. In this sense, it is investigated the influence of the insertion of $\S 3$ of art. 5o of the Federal Constitution, particularly on the hierarchical status of human rights treaties, as well as its relation to the provisions of $\S 2$ of the same device. The research
\end{abstract}

Keywords: Constitution. Human rights. Constitutional open clause. International treaties. Hierarchy.

\section{Sumário}

1 Introdução. 2 Direitos Fundamentais e Direitos Humanos. 3 Cláusula de Abertura. 4 A Interação do Direito Constitucional com o Direito Internacional. 50 Status Hierárquico dos Tratados Internacionais de Direitos Humanos Antes e Depois do § 3 do Artigo 5 da Constituição. 6 Considerações Finais. 7 Referências 


\section{INTRODUÇÃO}

O processo de democratização do Estado brasileiro proporcionou a reinserção do Brasil no cenário internacional de proteção dos direitos humanos, uma vez que com a democratização diversos tratados de direitos humanos puderam ser ratificados.

Assim, o aparato internacional de direitos humanos incrementa o sistema jurídico pátrio de proteção dos direitos fundamentais. Interessante notar neste ponto que algum desentendimento ainda pode ocorrer quanto à terminologia ora utilizada (direitos fundamentais e direitos humanos), por isso, como pressuposto para compreensão da discussão que se propõe, o ponto inicial do trabalho será diferenciar os conceitos.

Com efeito, a Constituição Federal de 1988 prevê em seu artigo 5ㅜㅡㄴ $\S 2^{\circ}$, que os direitos e garantias expressos na Carta não excluem outros decorrentes do regime, princípios e de tratados internacionais dos quais o Brasil seja parte. Esta é a chamada cláusula de abertura dos direitos fundamentais, pois agregam além dos direitos previstos no Título II, os demais direitos previstos na Constituição e nos Tratados Internacionais.

Nesse sentido, os tratados de direitos internacionais ganham relevo no ordenamento jurídico brasileiro, em especial no sistema de direitos e garantias fundamentais. Trata-se de um diálogo entre o Direito interno e a ordem jurídica internacional, que configura um verdadeiro Estado Constitucional Cooperativo.

A grande questão que surge nessa seara é sobre o status hierárquico dos tratados de direitos humanos, uma vez que o artigo $5^{\circ}$, $\S 3^{\circ}$, da Constituição Federal, inserido pela Emenda Constitucional n. 45/2004, dispõe que os tratados e convenções de direitos humanos que forem aprovados pelo Congresso Nacional, seguindo o processo de Emenda Constitucional, seriam equivalentes a elas. 
O objetivo geral do presente trabalho, portanto, é realizar uma reflexão sobre as consequências da inserção do $\S 3^{\circ}$ do $\operatorname{artigo} 5^{\circ}$ da Constituição Federal, em especial sobre o status hierárquico dos tratados de direitos humanos, bem como sua relação com o disposto no $\S$ $2^{\circ}$ do mesmo dispositivo. A análise parte-se em dois aspectos diversos: os tratados inseridos no ordenamento jurídico pátrio anteriormente à Emenda Constitucional no 45/2004 e aqueles inseridos posteriormente. Também será objeto de estudos a constitucionalidade do $\S 3^{\circ}$ do artigo $5^{\circ}$ da Constituição Federal.

A metodologia utilizada para o desenvolvimento da pesquisa foi a dedutiva e indutiva, com base na construção doutrinária e legislativa pátria.

Desde já ressalta-se que a presente abordagem não possui a pretensão de exaurir a temática, e sim conceder um panorama geral dos estudos desenvolvidos a respeito.

\section{DIREITOS FUNDAMENTAIS E DIREITO HUMANOS}

Como pressuposto para a compreensão do tema que se pretende desenvolver no decorrer deste trabalho, a abordagem dos conceitos de direitos fundamentais e de direitos humanos torna-se fundamental. Isso porque na temática dos direitos fundamentais diversas são as acepções e expressões que a doutrina usa para designar esses direitos e por conta da própria Constituição Federal, que faz referência tanto a direitos fundamentais quanto a direitos humanos em seu bojo, inclusive nos dispositivos que serão objeto de estudo no presente trabalho. 
Como alertam Emerique, Gomes e Sá (2006, p. 125), não há na doutrina consenso sobre qual terminologia seria a mais adequada: direitos naturais, direitos do homem, direitos individuais, direitos humanos fundamentais, direitos fundamentais do homem, liberdades públicas, dentre outras.

A Constituição Federal de 1988 utiliza diversas expressões em seu corpo, e nos parágrafos de especial interesse para a nossa temática empregam a expressão direitos fundamentais para tratar da cláusula de abertura (artigo $5^{\circ}, \S 2^{\circ}$ ) e direitos humanos quando dos tratados (artigo $5^{\circ}, \S 3^{\circ}$ ), o que reforçou a "corrente distinção entre direitos humanos e direitos fundamentais a partir do seu respectivo plano de reconhecimento e proteção jurídico-positivo” (SARLET, 2011a, p. 328).

Sarlet (2011b, p. 77) conceitua os direitos fundamentais como as posições jurídicas das pessoas que devido a sua importância e conteúdo foram retiradas da esfera de disponibilidade dos poderes instituídos pela Constituição. Melhor explica, um direito será fundamental quando houver relevância do bem jurídico tutelado na acepção do constituinte, devidamente acompanhado de uma atribuição de hierarquia normativa e de um regime jurídico especial para estes direitos (SARLET, 2011a, p. 76). Já os direitos humanos, conforme Macedo (1999, p. 127-128), fazem menção a uma esfera internacional e extraordenamento jurídico, recebidos dentro de um ordenamento jurídico e inscritos na Constituição. Ressalta, o autor, o aspecto moral desse direito especial, "daquilo que uma comunidade julga ser o mais importante de sua moral social, um ponto de coagulação do código moral” (MACEDO, 1999, p. 128).

O aspecto moral dos direitos humanos, todavia, não exclui a sua importância para a teoria e a prática do Direito. É o que informa Nino, ao afirmar que 
frente a la conclusión de que los derechos humanos son derechos de índole moral y no jurídica algunos podrían inferir que ellos son, en consecuencia, irrelevantes para la teoría y a la práctica del derecho. Sin embargo, esto es un error, y lo es aun cuando presupongamos un concepto positivista, o sea puramente descriptivo y no valorativo (1989, p. 23).

Em outra perspectiva, Borowski (2003, p. 30-33) ressalta a necessidade de se diferenciar os direitos humanos, os direitos fundamentais internacionais e os direitos fundamentais nacionais. Para este autor, os direitos humanos são direitos morais, pois têm sua validade pautada apenas na sua correção material. Por isso, têm validade universal e são atribuíveis a todos os homens do mundo. Já os direitos fundamentais internacionais constituem o intento de transformar os direitos humanos em direito positivo, pois consagrados em pactos e convenções. Por fim, os direitos fundamentais nacionais são aqueles direitos individuais positivados nas Constituições dos Estados democráticos constitucionais e também têm o intento de transformar o direito humano em direito positivo.

Marcelo Neves também considera relevante a diferenciação de “direitos fundamentais" e "direitos humanos” como pressuposto para desenvolver sua teoria sobre transconstitucionalismo pluridimensional dos direitos humanos (2012, p. 249). Nesse sentido, Neves compreende os direitos humanos como "expectativas normativas de inclusão jurídica de toda e qualquer pessoa na sociedade (mundial) e, portanto, de acesso universal ao direito enquanto subsistema social”, enquanto os direitos fundamentais são aqueles positivados constitucionalmente pelos Estados (2012, p. 252-253). Esclarece que ambos possuem conteúdo quase idêntico, diferenciando-se no âmbito de validade, pois os direitos fundamentais estão circunscritos a uma ordem constitucional, enquanto os direitos humanos têm a pretensão de valer para a ordem jurídica existente na sociedade mundial (NEVES, 2012, p. 253). Em proposta oposta, Teubner (2006, p. 175, 180) entende que os direitos fundamentais têm como propó- 
sito a inclusão da pessoa, ao passo que os direitos humanos estão ligados à exclusão do homem da sociedade, como ameaça à integridade do corpo e da alma do indivíduo em meio aos múltiplos processos de comunicação e globalização. Em que pesem as diferentes posições apontadas pela doutrina, nota-se uma tendência a utilizar a expressão direitos humanos no âmbito internacional, enquanto a expressão direitos fundamentais é empregada no âmbito da Constituição (MALISKA, 2013, p. 23). Essa preferência também é refletida nos tratados internacionais, como na Declaração de Direitos Humanos de Viena de 1993, que reitera a Declaração Universal dos Direitos Humanos e a Convenção Americana de Direitos Humanos (Pacto de San José da Costa Rica).

Nesta perspectiva, Sarlet, Marinoni e Mitidieiro conceituam e diferenciam direitos fundamentais e direitos humanos:

De acordo com o critério aqui adotado, o termo "direitos fundamentais" se aplica àqueles direitos (em geral atribuídos à pessoa humana) reconhecidos e positivados na esfera do direito constitucional positivado de determinado Estado, ao passo que a expressão "direitos humanos" guarda relação com os documentos de direito internacional, por referir-se àquelas posições jurídicas que se reconhecem ao ser humano como tal, independentemente de sua vinculação com determinada ordem constitucional, e que, portanto, aspiram à validade universal, para todos os povos e em todos os lugares, de tal sorte que revelam um caráter supranacional (internacional) e universal (SARLET; MARINONI; MITIDIEIRO, 2012, p. 249).

Importante notar, como afirma Piovesan (2011, p. 102), que tanto o Direito Internacional dos Direitos Humanos como a nova feição do Direito Constitucional ocidental (pautado em princípios e direitos fundamentais) surgem em resposta ao impacto das atrocidades então cometidas.

Enfim, as considerações aqui traçadas têm o fito de esclarecer a opção do constituinte na redação da Constituição nos dois parágrafos do artigo $5^{\circ}$ objetos do presente estudo. O parágrafo segundo utiliza a 
expressão direitos e garantia fundamentais, pois está tratando daqueles direitos estatuídos pela própria Constituição Federal e que têm validade dentro do ordenamento jurídico por ela instituído. Já o parágrafo terceiro faz menção a direitos humanos para se referir ao caráter internacional e extraterritorial de tais direitos.

\section{CLÁUSULA DE ABERTURA}

Não se olvida que o principal intento do presente trabalho seja explorar o $\S 3^{\circ}$ do artigo $5^{\circ}$, especialmente a questão do status dos tratados internacionais de direitos humanos, todavia faz-se necessário tecer algumas considerações sobre o $\S 2^{\underline{0}}$, uma vez que são complementares ao tema ora desenvolvido.

O contido no $\S 2^{\circ}$ do artigo $5^{\circ}$ da Constituição de 1988 não é novel no ordenamento jurídico brasileiro, pois tradicionalmente, desde a Constituição de 1891, é prevista a abertura constitucional nas Cartas.

O artigo 78 da Constituição de 1891 previa que os direitos e garantias nela previstos não excluíam direitos e garantias não enumerados, mas decorrentes de princípios. Segundo Mello (2001, p. 2), a finalidade pretendida com este artigo era evitar a interpretação de que a menção a direitos expressamente excluiria direitos outros.

Na mesma linha, o artigo 114 da Constituição de 1934 continuou a prever a abertura constitucional. Já o artigo 123 da Constituição de 1937 criou uma limitação para o uso da cláusula de abertura: “O uso desses direitos e garantias terá por limite o bem público, as necessidades da defesa, do bem-estar, da paz e da ordem coletiva, bem como as exigências da segurança da nação e do Estado em nome dela constituído e organizado nesta Constituição”. 
As Constituições de 1946 e 1967 retiram essa limitação e retornaram ao padrão das Constituições anteriores. A cláusula de abertura estava prevista nos artigos 144 e artigo 150, $\S 35$, respectivamente.

A Carta de 1988 inova ao incluir no rol de direitos alcançados pela abertura os direitos enunciados nos tratados internacionais de que o Brasil seja parte, proposta de Antônio Augusto Cançado Trindade, então consultor jurídico do Ministério das Relações Exteriores (MELLO, 2001, p. 2). Foi a primeira vez que uma Constituição brasileira previu abertura para normas de Direito Internacional.

Piovesan (2011, p. 104) afirma que esse processo de inclusão implica a incorporação de tais direitos pelo texto Constitucional. Vai mais além ao sustentar, por meio de interpretação sistemática e teleológica, que a Constituição atribuiu aos direitos internacionais, aqueles previstos em tratados internacionais de direitos humanos, a natureza de norma constitucional.

Antes de aprofundar o tema, interessante notar que a abertura da Constituição para além do catálogo não é exclusividade brasileira. Andrade (2004, p. 75), ao interpretar o n. 1 do artigo 16 da Constituição Portuguesa de 1976, informa que é possível a existência de outros direitos fundamentais, tanto em leis ordinárias quanto em normas internacionais e mais ainda em outras partes da Constituição.

Outrossim, a título informativo, a primeira cláusula de abertura surge com a $9^{\text {a }}$ Emenda à Constituição dos Estados Unidos da América: "The enumeration in the Constitucion, of certains rights, shall not be construed to deny or disparage others retained by the people" (ANDRADE, 2004, p. 76).

A cláusula de abertura implica o reconhecimento da coexistência dos conceitos formal e material de direitos fundamentais. Explica-se melhor, recorrendo-se aos argumentos de Andrade (2004, p. 77), o critério 
de fundamentalidade dos direitos não "corresponde à sua previsão ou especificação no texto constitucional e que se torna necessário um critério de substância para determinar o âmbito dessa matéria”.

Por essa razão Sarlet (2011b, p. 80) afirma que o artigo $5^{\circ}$, $\S 2^{\circ}$ consubstancia o entendimento e que para além de um conceito formal de direitos fundamentais, existe um conceito material, "no sentido de existirem direitos que, por seu conteúdo, por sua substância, pertencem ao corpo fundamental da Constituição de um Estado, mesmo não constando em seu catálogo" (2011b, p. 80).

Poderão, portanto, haver direitos fundamentais em sentido material mesmo não o sendo formalmente, uma vez que repousam fora do catálogo constitucional.

Emerique, Gomes e Sá bem explicam a diferença entre os dois conceitos:

Segundo Jorge Miranda os direitos fundamentais em sentido formal seriam aquelas posições jurídicas subjetivas das pessoas enquanto consagradas na Constituição. Esta primeira categoria está ligada ao direito constitucional positivo e ocupa lugar de destaque na ordem jurídica. São normas constitucionais submetidas aos limites formais e materiais da reforma constitucional. (...) Já o direito materialmente fundamental vem a ser aquele que é parte integrante da constituição material, contendo decisões fundamentais sobre a estrutura básica do Estado e da sociedade e que podem estar ou não na Constituição sob a designação de direitos fundamentais (2006, p. 131-132).

Outra questão, que não encontra consenso na doutrina, é se todos os direitos fundamentais formais podem ser considerados também materiais. Andrade (2004, p. 77) alerta que o critério material a ser usado é decisivo, pois poderá haver preceitos incluídos no catálogo que não constituam matéria de direitos fundamentais, e até porventura "direitos subjeti- 
vos só formalmente fundamentais". ${ }^{1}$ Em sentido contrário, doutrina Jorge Miranda (1998, p. 9), para o qual todos os direitos em sentido formal são também materiais. ${ }^{2}$ Embora exista esse debate na doutrina, como bem define Schier (2005, p. 15), a submissão ao regime especial não gera maiores dúvidas.

Essa é justamente a consequência mais importante do dispositivo ora estudado, um direito já previsto no ordenamento jurídico interno ou no âmbito internacional seja entendido como direito fundamental. A cláusula de abertura dos direitos fundamentais é de extrema importância por conta do regime jurídico especial de que os direitos fundamentais são dotados.

Sarlet (2011b, p. 60) afirma que os direitos fundamentais integram juntamente com a forma de Estado, do sistema de governo e da organização do poder, a essência do Estado constitucional, o elemento nuclear da Constituição material. Dessa maneira, continua, os direitos fundamentais podem ser entendidos como pressuposto, garantia e instrumento do princípio democrático.

Tendo em vista esse papel central dos direitos fundamentais, eles são revestidos de proteção máxima pela Constituição, uma vez que são cláusulas pétreas (artigo 60, $§ 4^{\circ}$, da $\mathrm{CF}$ ); submetem-se a um regime especial de restrição; são dotados de aplicabilidade imediata às entidades públicas e privadas (artigo $5^{\circ}, \S^{\circ}$, da $\mathrm{CF}$ ); integram o rol de cláusulas constitucionais sensíveis, dentre outras características (SCHIER, 2005, p. 15).

1 No mesmo sentido, ver: CANOTILHO, J. J. Gomes. Direito constitucional. 5. ed. Coimbra: Livrarias Almedina, 1992. p. 539 et seq.

2 MIRANDA, Jorge. Manual de Direito Constitucional. 2. ed. Coimbra: Coimbra, 1998. p. 9. T. 4. No mesmo sentido, ver: SARLET, Ingo W. A eficácia dos direitos fundamentais. 10. ed. Porto Alegre: Ed. Livraria do Advogado, 2011b. p. 82. 
A questão que resta investigar é o critério para identificar a materialidade ou fundamentalidade da norma para classificá-la como direito fundamental. São várias as propostas da doutrina, no entanto três são as principais.

A primeira, a teoria da equiparação, entende que um direito fundamental fora do catálogo galgaria tal status ao ser "equiparado" a um direito enunciado no Título II da Constituição. Assim, para que uma posição jurídica seja enquadrada como direito fundamental implícito é necessário que esteja prevista na Constituição, porém fora do Título II ou em tratado internacional de direito humano, e deverá ter conteúdo e dignidade equiparável a algum direito fundamental do catálogo (SARLET, 2011b, p. 92).।

Outra teoria muito difundida é a que pauta a fundamentalidade dos direitos no princípio da dignidade humana. Seriam fundamentais aqueles direitos fora do catálogo ligados ao princípio da dignidade da pessoa humana. Uma série de críticas, todavia, são desferidas a esta teoria, primeiramente porque quase todos os enunciados constitucionais têm algum tipo de ligação com a dignidade humana, o que tornaria praticamente toda a Constituição "fundamental". Como resposta, um segmento desta corrente restringiu o conceito para apenas aqueles direitos diretamente vinculados à dignidade humana. No entanto o problema ainda não restou resolvido, posto que a compreensão do que seria vinculação direta também é tormentosa. A única solução seria demonstrar no caso concreto a conexão entre o direito e a dignidade humana (SCHIER, 2005, p. 16). É o que se chama de exercício de atribuição de fundamentalidade.

A terceira corrente defende que além da dignidade humana os princípios fundamentais também justificam a fundamentalidade da norma. Um dos argumentos usados por Sarlet (2011b, p. 94) é que a própria redação do $\S 2^{\circ}$, do artigo $5^{\circ}$ da Constituição Federal ao falar em princípios, refere-se às disposições encetadas no Título I, artigos $1^{\circ}$ a $4^{\circ}$ da Carta, em que os Princípios Fundamentais delineiam os contornos básicos do 
Estado Social e Democrático de Direito brasileiro. Não se olvida que a dignidade humana é um princípio fundamental (fundamento da República) esculpido no artigo 1ำ, inciso III, da Constituição, todavia "não é o único nem, na perspectiva normativa, o mais importante princípio fundamental" (SCHIER, 2005, p. 16).

Os critérios de fundamentalidade ainda geram discussão na doutrina e foram trazidos a lume de maneira muito sucinta e resumida, tornando-se inviável no desenvolvimento do presente trabalho aprofundar a temática como merecida, em razão dos estritos limites desta investigação. Inclusive, na seara da abertura internacional, parte do problema foi resolvido com a inserção do $\S 3^{\circ}$ no artigo $5^{\circ}$ da Constituição Federal (SCHIER, 2005, p. 15), ao prever que os tratados internacionais de direitos humanos que forem internalizados pelo rito da emenda constitucional serão a ela equivalentes. Apenas parte do problema, porém, foi resolvido, posto que ainda resta a discussão sobre os tratados internalizados anteriormente à dita Emenda, assim como a própria interpretação do $§ 3^{\circ}$ do artigo $5^{\circ}$.

\section{A INTERAÇÃO DO DIREITO CONSTITUCIONAL COM O DIREITO INTERNACIONAL}

A inclusão dos tratados internacionais na cláusula de abertura dos direitos fundamentais traz uma nova perspectiva para o Direito Constitucional. Percebe-se uma abertura democrática da Constituição Federal e do próprio direito interno para o Direito Internacional. Nas palavras de Cançado Trindade (1991, p. 631), que articulou essa abertura na constituinte: "é alentador que as conquistas do Direito Internacional em favor da proteção do ser humano venham a projetar-se no Direito Constitucional, enriquecendo-o, e demonstra que a busca de proteção cada vez mais eficaz da pessoa humana encontra guarida nas raízes do pensamento tanto internacionalista quanto constitucionalista”. 
Bem explica Sarlet (2011a, p. 325) que é uma demanda prioritária a harmonização entre os ordenamentos dos diversos Estados em um mundo globalizado.

Resgatando as lições de Häberle (2007, p. 47), vivemos em um Estado Constitucional Cooperativo, no qual a coordenação entre os Estados deu lugar à cooperação, de modo a diminuir a dualidade do âmbito interno/externo e determinar uma abertura do Direito Internacional.

Assim, afirma Häberle (2007, p. 70) que é próprio de um Estado Constitucional Cooperativo a abertura para as relações internacionais, com objetivo de impor medidas eficientes no âmbito interno (permeabilidade), também no acento da abertura global dos direitos humanos (não mais cerrados no domínio reservado) e de sua realização "cooperativa”.

Logo, há um compromisso formal das Constituições em um Estado Cooperativo de proteção dos direitos humanos:

Ainda que críticas possam ser feitas quanto ao aparelhamento ideológico dos direitos humanos, não se pode negar que a existência de um marco normativo no plano internacional não seja importante e necessário, até mesmo para que o conceito propriamente seja debatido e as múltiplas interpretações sobre ele possam ocorrer. Portanto, o compromisso formal das Constituições com a proteção dos direitos humanos apresenta-se como um avanço institucional inquestionável, que, se ainda não está no seu modelo ideal, apresenta-se como um passo histórico importante. (...) O compromisso com os direitos humanos significa que o país se compromete a respeitá-los em seu território e que a abertura do texto constitucional irá possibilitar a atualização permanente das exigências que o desenvolvimento irá impor no tocante aos avanços de significado que a noção de direitos humanos poderá atingir. A ordem constitucional material do Estado abre-se à evolução do conceito de direitos humanos no plano internacional (MALISKA, 2013, p. 24-27). 
Galindo (2002, p. 90-92) delineou cinco fases em que se percebe a abertura das Constituições no mundo ao Direito Internacional A quinta seria aquela em que se favorece uma interpretação a toda normatividade do Direito Internacional dos direitos humanos. Quer-se dizer que as Constituições passaram a mencionar em seu corpo os direitos humanos no plano internacional, coma Constituição Federal de 1988 sendo um exemplo com o $\S 2^{\circ}$ do artigo $5^{\circ}$.

Para Canotilho (1992, p. 18), as Constituições são centros de legitimação e consensos de uma comunidade estatalmente organizada, mas isso não quer dizer que não deve se abrir progressivamente a uma "rede cooperativa de metanormas" e de normas provenientes de outros centros transnacionais. Dessa maneira, continua, os direitos humanos fornecem um novo paradigma ao constitucionalismo global, pois não se fala mais internacionalmente de relações entre Estados apenas, mas nas relações entre Estado e povo. Assim, há a emergência de um Direito Internacional dos direitos humanos ao qual as Constituições nacionais estão cada vez mais vinculadas em um contexto de abertura constitucionalNeste sentido, Maliska (2008, p. 120) afirma que o conceito de Estado Constitucional Cooperativo está presente na Constituição brasileira e entende que a incorporação dos tratados de direitos humanos a ela é uma marca própria deste tipo de Estado.

Outrossim, no mesmo campo do Estado Constitucional Cooperativo, muito se discute sobre o pluralismo de ordens jurídicas e da multiculturalidade em que se inserem os direitos humanos. Wolkmer (2006, p. 117), inspirado nos ensinamentos de Boaventura dos Santos, exprime a necessidade de se questionar a relação entre os direitos humanos e o Estado nacional, na medida em que o processo de globalização traz novas formas de dominação e exclusão que suplantam o território nacional, de maneira que as funções clássicas do Estado devem ser analisadas para se readequarem ao novo cenário mundial. Nesta perspectiva, o autor sus- 
tenta que os direitos humanos como processos de luta têm uma dimensão intercultural e de emancipação contra-hegemônica, por isso, enfatizando Herrera Flores, invoca uma nova fase histórica para os direitos humanos, na qual deve-se questionar a natureza individualista, essencialista, estatista e formalista dos direitos humanos (WOLKMER, 2006, p. 123). Neste contexto, não se ignoram os ensinamentos de Neves (2012, p. 256), que coloca os direitos humanos como questão central do transconstitucionalismo, cuja controvérsia emana das diversas e possíveis interpretações das normas e até mesmo práticas nos diversos sistemas constitucionais e internacionais. Neves afirma que o transconstitucionalismo instiga a cooperação e colisão entre os ordenamentos. Ora, até mesmo nas Cortes Constitucionais não é raro encontrar nos votos dos ministros, inclusive do Supremo Tribunal Federal, referências a sistemas constitucionais de outros países, assim como argumentações pautadas em tratados internacionais sequer assinados pelo BrasilDiante deste cenário de abertura constitucional à ordem internacional, uma série de discussões são travadas na doutrina e na jurisprudência a respeito dos reflexos que a incorporação dos tratados internacionais de direitos humanos causam.

\section{O STATUS HIERÁRQUICO DOS TRATADOS INTERNACIONAIS DE DIREITOS HUMANOS ANTES E DEPOIS DO § $3^{\circ}$ DO ARTIGO $5^{\circ}$ DA CONSTITUIÇÃO}

A análise do status hierárquico dos tratados internacionais de direitos humanos perpassa por duas fases distintas, antes e depois da inserção do $\S 3^{\circ}$ no artigo $5^{\circ}$ da Constituição Federal.

Da inteligência do disposto no $\S 2^{\underline{0}}$, já delineado nos tópicos anteriores, a doutrina divergia sobre o status hierárquico desses tratados. Existiam três possibilidades defendidas: natureza infraconstitucional, 
natureza constitucional e natureza supraconstitucional. ${ }^{3}$ Não havia um posicionamento legislativo sobre a questão na Constituição Federal de 1988.

Na tentativa de solucionar essa questão e complementar o $\S 2^{\circ}$, foi inserido o $\S 3^{\circ}$ no artigo $5^{\circ}$, que dispõe sobre a forma de incorporação ao direito interno dos tratados internacionais: "os tratados e convenções internacionais sobre direitos humanos que forem aprovados, em cada Casa do Congresso Nacional, em dois turnos, por três quintos dos votos dos respectivos membros, serão equivalentes às emendas constitucionais”.

Tendo em vista o teor do dispositivo, a discussão ganhou novos contornos, tanto em relação aos tratados incorporados anteriormente à Emenda Constitucional 45/2004 que inseriu o $§ 3^{\circ}$, quanto a problemas gerados no âmbito do novo processo instituído. ${ }^{4}$

3 A corrente majoritária na doutrina brasileira era a de status constitucional. Neste sentido: "Os tratados internacionais de proteção dos direitos humanos ratificados pelo Estado brasileiro são fonte do sistema constitucional de proteção de direitos, pois ingressam na ordem jurídica brasileira com indole e nível constitucional, conferindo suporte axiológico à interpretação de todo o nosso Direito interno. Além do status de norma constitucional, tais tratados têm aplicação imediata na ordem jurídica brasileira a partir da ratificação. Além disso, os direitos e garantias advindos desses instrumentos internacionais, uma vez integrados ao ordenamento brasileiro, passam a ser cláusulas pétreas do texto constitucional, não podendo ser abolidos sequer por emenda à Constituição. Conseqüentemente os tratados internacionais de proteção dos direitos humanos em que a República Federativa do Brasil seja parte são insusceptíveis de denúncia" (MAZZUOLI, 2002, p. 124).

4 Embora não seja o norte deste trabalho, consigna-se que a constitucionalidade da Emenda n. 45/2004 é questionada pela doutrina: "Por outro lado, argumenta-se que a inovação trazida pela EC 45 é inconstitucional por violar os limites materiais à reforma constitucional, no sentido de que se acabou dificultando o processo de incorporação dos tratados internacionais sobre direitos humanos e chancelando o entendimento de que os tratados não incorporados pelo rito das emendas constitucionais teriam hierarquia meramente legal, de tal sorte que restou restringido, dessa forma, o próprio regime jurídico-constitucional dos direitos fundamentais oriundos dos tratados" (SARLET, 2011a, p. 330). 
A discussão ganha relevos práticos quando se percebe que foram 15 tratados de direitos humanos ratificados pelo Brasil desde $1988 .{ }^{5}$ Ora, até o momento apenas um tratado foi ratificado após a Emenda Constitucional n. 45/2004, razão pela qual o status hierárquico dos tratados anteriores é de interesse investigativo.

São quatro as correntes defendidas pela doutrina e pela jurisprudência nesta seara. A primeira teoria é a menos difundida na doutrina nacional, sendo mais desenvolvida no âmbito dos internacionalistas, que é a do status supraconstitucional dos tratados internacionais de direitos humanos. O principal expoente desta teoria é o professor Celso de Albuquerque Mello, para o qual uma norma de Direito Internacional prevalece sobre a norma constitucional, "mesmo naquele caso em que uma norma constitucional posterior tente revogar uma norma internacional constitucionalizada” (MELLO, 2001, p. 25).

Em que pese considerarem a teoria desenvolvida por Mello interessante, Emerique e Guerra (2008) apontam para a dificuldade de concretização na ordem constitucional brasileira em razão do princípio da suprema-

5 Convenção Interamericana para Prevenir e Punir a Tortura, em 20 de julho de 1989; Convenção contra a Tortura e outros Tratamentos Cruéis, Desumanos ou Degradantes, em 28 de setembro de 1989; Convenção sobre os Direitos da Criança, em 24 de setembro de 1990; d) do Pacto Internacional dos Direitos Civis e Políticos, em 24 de janeiro de 1992; Pacto Internacional dos Direitos Econômicos, Sociais e Culturais, em 24 de janeiro de 1992; Convenção Americana de Direitos Humanos, em 25 de setembro de 1992; Convenção Interamericana para Prevenir, Punir e Erradicar a Violência contra a Mulher, em 27 de novembro de 1995; Protocolo à Convenção Americana referente à Abolição da Pena de Morte, em 13 de agosto de 1996; Protocolo à Convenção Americana referente aos Direitos Econômicos, Sociais e Culturais (Protocolo de San Salvador), em 21 de agosto de 1996; Convenção Interamericana para Eliminação de todas as formas de Discriminação contra Pessoas Portadoras de Deficiência, em 15 de agosto de 2001; Estatuto de Roma, que cria o Tribunal Penal Internacional, em 20 de junho de 2002; Protocolo Facultativo à Convenção sobre a Eliminação de todas as formas de Discriminação contra a Mulher, em 28 de junho de 2002; do Protocolo Facultativo à Convenção sobre os Direitos da Criança e sobre o Envolvimento de Crianças em Conflitos Armados, em 27 de janeiro de 2004; Protocolo Facultativo à Convenção sobre os Direitos da Criança sobre Venda, Prostituição e Pornografia Infantis, também em 27 de janeiro de 2004; e Protocolo Facultativo à Convenção contra a Tortura, em 11 de janeiro de 2007. 
cia formal e material da Constituição de 1988 sobre todo o ordenamento jurídico. A mesma crítica é tecida pelo ministro Gilmar Mendes em seu voto no $R E n^{\circ}$ 466.343-1. Inclusive aponta decisões anteriores do Supremo Tribunal Federal que ditam a supremacia da Constituição Federal perante os tratados e destaca o controle de constitucionalidade destes (RHC n ${ }^{\circ}$ 79.785/2002 - ministro Sepúlveda Pertence).

A segunda teoria também não conta atualmente com muitos adeptos. É a que considera os tratados de direitos humanos com natureza de lei ordinária. Não se olvida que os tratados internacionais, de maneira geral, têm status infraconstitucional. Tal afirmação tem fundamento no artigo 102, III, b, da Constituição Federal, que confere ao Supremo Tribunal Federal a competência para julgar, em Recurso Extraordinário, decisões que declararem a inconstitucionalidade de tratado ou lei federal, aplicando-se, inclusive, a regra de antinomia jurídica de que lei posterior revoga lei anterior entre os diplomas normativos. Desde 1977 essa é a posição do Supremo Tribunal Federal, devidamente desenvolvida no Recurso Extraordinário n. 80.004.

Ocorre que este posicionamento foi aplicado pelo Supremo Tribunal Federal também quando da temática de direitos humanos, em que pese a decisão supracitada ter sido anterior à Constituição Federal e em tema comercial. No julgamento do HC n. 72.131-RJ, o Supremo Tribunal Federal entendeu que por legislação interna a prisão civil poderia ser mantida no ordenamento jurídico, embora seja proibida no âmbito do Pacto de San José da Costa Rica, tratado ratificado e internalizado pelo Brasil. Veja-se a ementa:

Habeas corpus. Alienação fiduciária em garantia. Prisão civil do devedor como depositário infiel. - Sendo o devedor, na alienação fiduciária em garantia, depositário necessário por força de disposição legal que não desfigura essa caracterização, sua prisão civil, em caso de infidelidade, se enquadra na ressalva contida na parte final do artigo $5^{\circ}$, LXVII, da Constituição de 1988. - Nada interfere na questão do depositário 
infiel em matéria de alienação fiduciária o disposto no $\S 7^{\circ}$ do artigo $7^{\circ}$ da Convenção de San José da Costa Rica. Habeas corpus indeferido, cassada a liminar concedida.

Este entendimento foi reiterado posteriormente pelo Supremo Tribunal Federal, embora não seja mais esse o entendimento adotado pela Corte atualmente.

A guinada de entendimento da Corte Máxima deu-se no julgamento do Recurso Extraordinário n. 466.343, que configura a terceira corrente a ser estudada.

Os ministros do Supremo, capitaneados pelo entendimento do ministro Gilmar Mendes, decidiram que os Tratados de Direitos Humanos ratificados anteriormente ao 45/2004 teriam nível supralegal, porém infraconstitucional. Logo, estão acima da legislação ordinária interna, mas abaixo da Constituição Federal.

Nesse sentido, a legislação infraconstitucional existente ao tempo da ratificação do tratado de direito humano que lhe seja conflitante tem sua eficácia paralisada, nos termos do artigo 652 do Código Civil. Já a legislação posterior à ratificação de tais tratados serão objeto de controle de convencionalidade. ${ }^{6}$

O julgamento do paradigma versou sobre a (in) constitucionalidade da prisão civil do devedor fiduciário em contrato de alienação fiduciária em garantia, em face do que dispõe o artigo $5^{\circ}$, inciso LXVII, da Constituição Federal. Embora a votação tenha sido unânime no sentido de rejeitar o recurso e alguns ministros tenham entendido pela hierarquia constitucio-

6 Sobre o tema: MAZZUOLI, Valério de Oliveira. Teoria geral do controle de convencionalidade no direito brasileiro. Revista de Informação Legislativa, Brasília, a. 46, n. 181 jan./ mar. 2009. 
nal dos tratados de direitos humanos, ${ }^{7}$ restou vencedora a tese da supralegalidade pelo argumento de que alçar os tratados ao grau constitucional tornaria incontrolável o processo de ampliação do bloco de constitucionalidade, uma vez que de difícil definição quais são os direitos fundamentais.

Sustenta Gilmar Mendes que a inclusão do $§ 3^{\circ}$ no artigo $5^{\circ}$ na Constituição Federal "trata-se de uma declaração eloqüente de que os tratados já ratificados pelo Brasil, anteriormente à mudança constitucional, e não submetidos ao processo legislativo especial de aprovação no Congresso Nacional, não podem ser comparados às normas constitucionais”.Ao mesmo tempo, ressalta que o dispositivo exalta uma posição privilegiada dos tratados de direitos humanos no ordenamento jurídico (RE 466.343-1/ SP, j. 03.12.2008, rel. Cezar Peluso, p. 1.144).

Assim, a Corte deu um passo à frente ao deixar de considerar os tratados de direitos humanos como normas infraconstitucionais e entender que tal posicionamento não encontrava mais lugar ante um Estado aberto e cooperativo que privilegia as normas internacionais protetivas da dignidade do ser humano.

A doutrina nacional, todavia, almejava uma posição mais vanguardista, por isso restou muito criticada, conforme expõe Maliska:

Nesse ponto, o entendimento do voto merece ser criticado, pois a desconsideração da dimensão material de vinculação dos Tratados de Direitos Humanos destoa da melhor doutrina sobre a matéria e,

\footnotetext{
7 O ministro Celso de Mello divergiu do conteúdo do voto do ministro Gilmar Mendes e em seu voto consignou que os tratados de direitos humanos têm grau de norma constitucional, mas diferenciou os argumentos conforme o tempo de ratificação do tratado: 1) aqueles ratificados antes da Constituição Federal de 1988 devem ser recepcionados como norma constitucional; 2) entre a promulgação da Constituição Federal de 1988 e a Emenda Constitucional $\mathrm{n}^{\circ}$. 45/2004, os tratados ratificados são formalmente materiais por força do $\S 2^{\circ}$ do artigo $5^{\circ}$; e 3) após a inclusão do $\S 3^{\circ}$ no artigo $5^{\circ}$, para serem considerados constitucionais, os tratados devem passar pelo processo previsto no dispositivo em comento. Também o ministro Celso Peluso, relator do recurso, divergiu do voto vencedor ao considerar que os tratados de direitos humanos são normas sempre materialmente constitucionais e passarão a ser formalmente materiais caso passem pelo processo previsto no $\S 3^{\circ}$ do artigo $5^{\circ}$.
} 
inclusive, afasta-se da jurisprudência do próprio STF, que reconheceu o princípio da abertura material do catálogo de direitos fundamentais da Constituição, quando julgou a Ação Direta de Inconstitucionalidade n. 939-7, publicada no Diário de Justiça da União, em 18 de março de 1994. (...) A preocupação do Supremo Tribunal Federal em garantir o Princípio da Supremacia da Constituição é bem-vinda e deve ser mantida nas relações em que o país, cada vez mais, vem travando no plano internacional. No entanto, a questão, a saber, é se não haveria como garantir essa supremacia, dando plena eficácia ao disposto no parágrafo $2^{\circ}$ do artigo $5^{\circ}$ da Constituição, conferindo aos Tratados de Direitos Humanos já ratificados a condição de, se não formalmente fundamentais em virtude da Emenda Constitucional n. 45, por força da cláusula tempus regit actum, ao menos como materialmente fundamentais, uma vez pertencerem ao "corpo fundamental da Constituição" (MALISKA, 2013, p. 115-116).

Interessante notar que em 2016, mesmo em nova composição, o ministro Luiz Edson Fachin, membro do Supremo Tribunal Federal ingresso após a finalização do julgamento do RE $\mathrm{n}^{0}$. 466.341-1, reiterou a posição de supralegalidade dos tratados de direitos humanos em seu voto no julgamento do pedido de Extradição n ${ }^{0} 1.362$ sem muito debate.

Os críticos à posição da Corte Suprema, em sua maioria, defendem a natureza constitucional dos tratados internacionais de direitos humanos, pautados principalmente no $\S 2^{\circ}$ do artigo $5^{\circ}$ da Constituição Federal. Esta é a quarta e última corrente.

Conforme leciona Piovesan (2011, p. 116-117), conferir hierarquia constitucional aos tratados de direitos humanos, observando-se o princípio da prevalência da norma mais favorável, ${ }^{8}$ é a interpretação que melhor se

8 Neste mesmo sentido, Cançado Trindade exalta a primazia da norma, interna ou externa, que melhor proteja as vítimas e violações de direitos humanos: "A tese que sustento, como venho fazendo já por mais de vinte anos em meus escritos, é, em resumo, no sentido de que - primeiro, os tratados de direitos humanos, que se inspiram em valores comuns superiores (consubstanciados na proteção do ser humano) e dotados de mecanismos próprios de super- 
coaduna com a Constituição de 1988. Afirma que os tratados de direitos humanos têm como objetivo a salvaguarda dos direitos do ser humano e não das prerrogativas de Estado, por isso o caráter especial desses tratados justifica o status constitucional a eles atribuídos.

Cabe destacar a lição de Cançado Trindade (1997, p. 498), que idealizou o dispositivo, no sentido de que a cláusula de abertura estatuída pelo parágrafo segundo em conjunto com o parágrafo primeiro (que trata da efetividade imediata dos direitos fundamentais) demonstram uma tendência das Constituições latino-americanas em conceder tratamento especial no plano interno aos direitos humanos já consagrados no plano internacional, de modo a integrar o ordenamento jurídico constitucional e poderem ser imediatamente exigíveis no plano interno.

Nesse sentido, Ramina (2006, p. 87) defende que o artigo $5^{\circ}, \S 2^{\underline{0}}$ não deixa dúvidas acerca da hierarquia constitucional dos tratados de direitos humanos. Complementa Mazzuoli (2001, p. 14) que "à medida em que os Estados assumem compromissos mútuos em convenções internacionais, que diminuem a competência discricionária de cada contratante, eles restringem sua soberania e isto constitui uma tendência do constitucionalismo contemporâneo”. Piovesan colaciona quatro argumentos a favor da constitucionalidade dos tratados anteriores à Emenda Constitucional 45/2004:

\footnotetext{
visão que se aplicam consoante a noção de garantia coletiva, têm caráter especial, que os diferenciam dos demais tratados, que regulam interesses reciprocos entre os Estados-partes e são por estes próprios aplicados - com todas as conseqüências jurídicas, que daí advêm nos planos do direito internacional e do direito interno; segundo, o direito internacional e o direito interno mostram-se em constante interação no presente contexto de proteção, na realização do propósito convergente e comum da salvaguarda dos direitos do ser humano; e terceiro, na solução de casos concretos, a primazia é da norma que melhor proteja as vítimas de violações de direitos humanos, seja ela de origem internacional ou interna" (CANÇADO TRINDADE, 1999, p. 5-6).
} 
a) a interpretação sistemática da Constituição, de forma a dialogar com os $\S \S 2^{\circ}$ e $3^{\circ}$ do art. $5^{\circ}$, já que o último não revogou o primeiro, mas deve, ao revés, ser interpretação à luz do sistema constitucional; b) a lógica e racionalidade material devem orientar a hermenêutica dos direitos humanos; c) a necessidade de evitar interpretações que apontem a agudos anacronismos da ordem jurídica; e d) a teoria geral da recepção do Direito brasileiro (2011, p. 125).

Conforme este último argumento de Piovesan, Schier (2006a, p. 3) aplica o argumento do tempus regit actum para defender a constitucionalidade dos tratados incorporados anteriormente à Emenda n. 45/2004. A tese desenvolvida argumenta que os tratados foram recepcionados conforme o procedimento válido à época da incorporação, por isso devem assumir automaticamente o status de emenda constitucional.

A tese foi recepcionada pelo ministro José Delgado no RHC 18799/ RS - Recurso Ordinário em Habeas Corpus 2005/0211458-7:

Constitucional. Processual penal. Recurso Ordinário em habeas corpus. Execução fiscal. Depositário infiel. Penhora sobre o faturamento da empresa. Constrangimento ilegal. Emenda Constitucional no 45/2004. Pacto de São José da Costa Rica. Aplicação Imediata. Ordem concedida. Precedentes.

c) o $\S 3^{\circ}$ do art. $5^{\circ}$ da $\mathrm{CF} / 88$, acrescido pela $\mathrm{EC} \mathrm{n}^{\circ} 45$, é taxativo ao enunciar que "os tratados e convenções internacionais sobre direitos humanos que forem aprovados, em cada Casa do Congresso Nacional, em dois turnos, por três quintos dos votos dos respectivos membros, serão equivalentes às emendas constitucionais”. Ora, apesar de à época o referido Pacto ter sido aprovado com quorum de lei ordinária, é de se ressaltar que ele nunca foi revogado ou retirado do mundo jurídico, não obstante a sua rejeição decantada por decisões judiciais. De acordo com o citado $\S 3^{\circ}$, a Convenção continua em vigor, desta feita com força de emenda constitucional. A regra emanada pelo dispositivo em apreço 
é clara no sentido de que os tratados internacionais concernentes a direitos humanos nos quais o Brasil seja parte devem ser assimilados pela ordem jurídica do país como normas de hierarquia constitucional; d) não se pode escantear que o $§ 1^{\circ}$ supra determina, peremptoriamente, que "as normas definidoras dos direitos e garantias fundamentais têm aplicação imediata”. Na espécie, devem ser aplicados, imediatamente, os tratados internacionais em que o Brasil seja parte;

e) o Pacto de São José da Costa Rica foi resgatado pela nova disposição constitucional (art. $5^{\circ}, \S 3^{\circ}$ ), a qual possui eficácia retroativa; $[\ldots]$

Estas são as posições para os tratados internacionais de direitos humanos recepcionados anteriormente à Emenda Constitucional n. 45/2004. A questão que resta discutir refere-se ao status dos tratados recepcionados após a inserção do $\S 3^{0}$ no artigo $5^{\circ}$ da Constituição Federal.

Depreende-se do dispositivo inserido que está assegurada "em princípio e em sendo adotado tal procedimento, a condição de direitos formal e materialmente fundamentais aos direitos consagrados no plano das convenções internacionais” (SARLET, 2011a, p. 328).

Com efeito, uma vez ratificado e internalizado o tratado de direito humano pelo rito estabelecido no $\S 3^{\circ}$ do artigo $5^{\circ}$, as normas por ele estatuídas ganham status de emenda constitucional e podem ser consideradas verdadeiros direitos fundamentais.

Neste ponto, reprisa-se o debate do segundo tópico do presente artigo. O direito humano consagrado em documentos internacionais é internalizado e passa a ser considerado um direito fundamental tutelado no direito interno (NEVES, 2012, p. 253)

Sarlet (2011a, p. 336) entende que o $§ 3^{\circ}$ do artigo $5^{\circ}$ da Constituição Federal significou um avanço ao assegurar a hierarquia constitucional equivalente às emendas constitucionais para os tratados internacionais de 
direitos humanos, uma vez que o Supremo Tribunal Federal consagrou a hierarquia supralegal para os tratados. Observa, todavia, que ainda não restou resolvida a questão do conflito entre tratados e normas constitucionais originárias. Por isso, aventa a possibilidade de inconstitucionalidade do parágrafo inserido.

Nesta perspectiva, o autor sustenta que apesar de o parágrafo acrescentado garantir o status de emenda para os tratados de direitos humanos que passarem pelo processo legislativo instituído, a cláusula de abertura estatuída pelo $\S 2^{\circ}$ do artigo $5^{\circ}$ da Constituição Federal já garante o patamar constitucional para essas normas. Assim, Sarlet entende que não se pode falar em hierarquia abstrata entre normas formalmente constitucionais e normas materialmente constitucionais, por isso o referido $\S 3^{\circ}$ seria desnecessário e, inclusive, passível de arguição de inconstitucionalidade "pelo simples fato de contrastar com os limites materiais ao poder de reforma da Constituição” (SARLET, 2011a, p. 327).

Para Sarlet (2011a, p. 341), portanto, não importa se o tratado de direitos humanos foi incorporado ou não pelo processo de emenda constitucional, eles possuem status materialmente constitucional e em caso de eventual situação de conflito a solução seria utilizar das diretrizes hermenêuticas, tendo como norte a solução mais afinada com a máxima salvaguarda da dignidade da pessoa humana. Por isso, defende que o $\S$ $3^{\circ}$ deveria ter-se resignado a chancelar a incorporação automática e com hierarquia constitucional para todos os tratados de direitos humanos, e em caso de conflito aplicar a posição mais benéfica para o ser humano.

A mesma crítica é tecida por Piovesan (2011, p. 123-124), ao entender que o mais adequado seria que o $\S 3^{\circ}$ tivesse endossado a hierarquia constitucional de todos os tratados de direitos humanos, como faz a Constituição argentina. De qualquer forma, a autora entende que o $\S 3^{\circ}$ apenas reforça a natureza constitucional dos tratados, pois o quórum qualificado 
apenas irá realizar uma constitucionalização formal dos tratados no âmbito interno, uma vez que por força do $\S 2^{\circ}$ do artigo $5^{\circ}$ todos os tratados de direitos humanos são materialmente constitucionais.

Nesse sentido, Schier (2006b, p. 345) observa que o $\S 3^{\circ}$ do artigo $5^{0}$ “é desprovido de sentido prático pois, em última análise, apenas repete, em outro contexto, o procedimento que já estava definido no artigo 60 da Lei Fundamental”.

Com efeito, a argumentação tecida pelos autores citados perpassa pela análise da fundamentalidade material e formal dos direitos fundamentais, por isso a compreensão da temática no início do texto era essencial para a conclusão a que se chega.

Constata-se, portanto, que a despeito da inclusão do $\S 3^{\circ}$, a atribuição de fundamentalidade das normas advindas dos tratados de direitos humanos continua motivada na cláusula de abertura prevista no $\S 2^{\circ}$ do mesmo artigo.

Ora, quer-se ressaltar que diante da interpretação sistemática e teleológica da Constituição, conforme sustentam Sarlet (2011a, p. 327) e Piovesan (2011, p. 125), o grau constitucional das normas de direitos humanos oriundas de tratados internacionais firmados pelo Brasil originariamente é garantido pela cláusula de abertura do $\S 2^{\circ}$ do artigo $5^{\circ}$, não podendo o constituinte reformador limitar a garantia constitucional sob risco de ofensa à cláusula pétrea.

Outrossim, evita-se falar em inconstitucionalidade da Emenda Constitucional $n^{\circ}$. 45/2004, uma vez que é possível atribuir-lhe interpretação conforme a Constituição: os tratados internacionais de direitos humanos ratificados pelo Brasil são sempre normas materialmente constitucionais pelo seu conteúdo diante o $\S 2^{\circ}$ do artigo $5^{\circ}$, mas serão também formalmente constitucionais se passarem pelo processo de internalização disposto no $\S 3^{\underline{o}}$. 
Contrariando, portanto, a atual orientação do Supremo Tribunal Federal, a doutrina majoritária entende que os tratados de direitos humanos sempre têm hierarquia de norma constitucional, quer tenham sido incorporados anteriormente ou após a inserção do $\S 3^{\circ}$ no $\operatorname{artigo~} 5^{\circ}$ da Constituição Federal.

Interessante, por fim, o alerta que fazem Maués e Magalhães (2016, p. 81,106$)$, no sentido de que, considerando que as normas internacionais uma vez incorporadas ao ordenamento interno devem ser garantidas pelo Poder Judiciário e o Estado pode ser demandando nas Cortes Internacionais sobre seu descumprimento, a posição do Supremo Tribunal Federal de prevalência absoluta da Constituição Federal ante os tratados pode trazer consequências severas na seara internacional para o país quando se estiver diante de um conflito inconciliável.

\section{CONSIDERAÇÕES FINAIS}

No presente trabalho realizou-se uma reflexão sobre as consequências da inserção do $\S 3^{\circ}$ no artigo $5^{\circ}$ da Constituição Federal, em especial sobre o status hierárquico dos tratados de direitos humanos, bem como sua relação com o disposto no $\S 2^{\circ}$ do mesmo dispositivo.

Tendo em vista a utilização pela Constituição Federal e nos dois dispositivos analisados dos termos "direitos fundamentais" e "direitos humanos”, necessário se fez diferenciá-los. Nesse sentido, a expressão “direitos humanos" refere-se a uma esfera internacional, sendo de utilização preferencial pelos documentos internacionais, enquanto os "direitos fundamentais" referem-se aos direitos positivados no âmbito de uma Constituição. 
De posse dessa premissa, percebeu-se que o artigo $5^{\circ}$, $\S 2^{\underline{o}}$, da Constituição representa uma verdadeira abertura do sistema constitucional de direitos fundamentais, tanto no sentido de reconhecer direitos além do Título II, como recepcionar direitos presentes em tratados internacionais ratificados pelo Brasil.

Outra conclusão foi a de que este dispositivo implica uma dupla fundamentalidade dos direitos humanos, ou seja, em sentido formal e material. Esta classificação foi de especial importância para as conclusões alcançadas na interpretação do $\S 3^{\circ}$ do artigo $5^{\circ}$ da Constituição Federal.

Outrossim, a inclusão dos tratados internacionais na cláusula de abertura dos direitos fundamentais traz uma nova perspectiva para o Direito Constitucional. Percebe-se uma abertura democrática da Constituição Federal e do próprio direito interno para o Direito Internacional. Essa abertura traduz-se em um verdadeiro Estado Constitucional Cooperativo, pois há um compromisso formal da Constituição em assegurar a proteção aos direitos humanos.

Não se olvida que para cumprir esse compromisso formal assinalado pelo $\S 2^{\circ}$, a discussão travada pela doutrina sobre o status hierárquico dos tratados internacionais de direitos humanos ganha relevo.

Perpassadas as diversas correntes doutrinárias e jurisprudências, ao final percebeu-se que atualmente ainda não há uma posição pacífica sobre a interpretação dos $\S \S 2^{\circ}$ e $3^{\circ}$ do artigo $5^{\circ}$ da Constituição Federal. Apesar de o Supremo Tribunal Federal permanecer na orientação da supralegalidade dos tratados ratificados anteriormente à Emenda Constitucional $\mathrm{n}^{\circ}$. 45/2004, sem qualquer indício de mudanças, a doutrina pátria continua a sustentar o status constitucional material das normas internacionais de direitos humanos. 
Assim, apesar da tentativa de dissipar as discussões sobre o grau hierárquico dos tratados de direitos humanos com a inclusão do $\S 3^{\circ}$ no artigo $5^{\circ}$, a celeuma continua na seara acadêmica, que apenas aguarda uma nova oportunidade de o Supremo Tribunal Federal debater a questão diante de um conflito irreconciliável entre uma norma constitucional e um tratado de direitos humanos ratificado pelo Brasil.

\section{REFERÊNCIAS}

ANDRADE, José Carlos Vieira de. Os direitos fundamentais na Constituição Portuguesa de 1976. 3. ed. Coimbra: Almedina, 2004.

BOROWSKI, Martin. La estrutura de los derechos fundamentales. Bogotá: Universidad Externado de Colombia, 2003.

CANÇADO TRINDADE, Antônio Augusto. A proteção internacional dos direitos: fundamentos jurídicos e instrumentos básicos. São Paulo: Saraiva, 1991.

. Memorial em prol de uma nova mentalidade quanto à proteção dos direitos humanos nos planos internacional e nacional. In: MELLO, Celso D. de Albuquerque; TORRES, Ricardo Lobo. Arquivos de direitos humanos. Rio de Janeiro: Renovar, 1999.

. Tratado de direito internacional dos direitos humanos. Porto Alegre: Sérgio Fabris, 1997. p. 498.

CANOTLHO, J. J. Gomes. Direito constitucional. 5. ed. Coimbra: Livrarias Almedina, 1992.

EMERIQUE, Lilian Márcia Balmant; GOMES, Alice Maria de Menezes; SÁ, Catharine Fonseca de. A abertura constitucional a novos direitos fundamentais. In: Revista da Faculdade de Direito de Campos, ano VII, n. 8, jun. 2006.

EMERIQUE, Lilian Márcia Balmant; GUERRA, Sidney. A incorporação dos tratados internacionais de direitos humanos na ordem jurídica brasileira. Revista Jurídica, Brasília, v. 10, n. 90, ed. esp., p. 1-34, abr./maio 2008. 
GALINDO, George Rodrigo Bandeira. Tratados internacionais de direitos humanos e constituição brasileira. Belo Horizonte: Del Rey, 2002.

HÄBERLE, Peter. Estado constitucional cooperativo. Rio de Janeiro: Renovar, 2007.

MACEDO, Ubiratan Borges de. Direitos humanos e sua teoria. In: MELLO, Celso D. de Albuquerque; TORRES, Ricardo Lobo. Arquivos de direitos humanos. Rio de Janeiro: Renovar, 1999.

MALISKA, Marcos Augusto. Fundamentos da Constituição. Abertura. Cooperação. Integração. Curitiba: Juruá, 2013.

Constituição e cooperação normativa no plano internacional: reflexões sobre o voto do ministro Gilmar Mendes no Recurso Extraordinário n. 466.343-1. Espaço Jurídico, Joaçaba, v. 9, n. 2, p. 113-124, jul./dez. 2008.

MAUÉS, Antônio Moreira; MAGALHÃES, Breno Baía. A recepção dos Tratados de Direitos Humanos pelos Tribunais Nacionais: sentenças paradigmáticas de Colômbia, Argentina e Brasil. Direito, Estado e Sociedade, n. 48, p. 76-112, jan./jun. 2016.

MAZZUOLI, Valério de Oliveira. Os Tratados Internacionais de Direitos Humanos como fonte do sistema constitucional de proteção de direitos. $R$. CEJ, Brasília, n. 18, p. 120-124, jul./set. 2002.

. Direito internacional: Tratados e Direitos Humanos Fundamentais na Ordem Jurídica Brasileira. Rio de Janeiro: América Jurídica, 2001.

. Teoria geral do controle de convencionalidade no direito brasileiro. Revista de Informação Legislativa, Brasília, a. 46, n. 181, jan./mar. 2009.

MELLO, Celso de Albuquerque. O $\S 2^{\circ}$ do art. $5^{\circ}$ da Constituição Federal. In: TORRES, Ricardo Lobo (Org.). Teoria dos Direitos Fundamentais. 2. ed. rev. e ampl. Rio de Janeiro: Renovar, 2001.

MIRANDA, Jorge. Manual de Direito Constitucional. 2. ed. Coimbra: Coimbra, 1998. T. 4.

NEVES, Marcelo. Transconstitucionalismo. São Paulo: Martins Fontes, 2012.

NINO, Carlos Santiago. Ética y Derechos Humanos. Buenos Aires: Ed. Astrea, 1989. 
PIOVESAN, Flávia. Direitos Humanos e o Direito Constitucional Internacional. 12. ed. rev. e atual. São Paulo: Saraiva, 2011.

VIEIRA, Renato Stanziola; PIOVESAN, Flávia. Justiciabilidade dos direitos sociais e econômicos no Brasil: desafios e perspectivas. Araucária: Revista Iberoamericana de filosofía, política y humanidades, $\mathrm{n}^{\circ}$. 15, p. 128-146, abril, 2006. RAMINA, Larissa. Direito Internacional Convencional: tratados em geral, tratados em matéria tributária e tratados de direitos humanos. Ijuí: Ed. Unijuí, 2006. SARLET, Ingo W. Considerações a respeito das relações entre a Constituição Federal de 1988 e os Tratados Internacionais de Direitos Humanos. Espaço Jurídico, Joaçaba, v. 12, n. 2, p. 325-344, jul./dez. 2011a.

. A eficácia dos direitos fundamentais. 10. ed. Porto Alegre: Livraria do Advogado, 2011b.

SARLET, Ingo W.; MARINONI, Luiz Guilherme; MITIDIERO, Daniel. Curso de direito constitucional. São Paulo: Editora Revista dos Tribunais, 2012.

SCHIER, Paulo Ricardo. Novos desafios da filtragem constitucional no momento do neoconstitucionalismo. Revista Eletrônica de Direito do Estado, n. 4, p. 15, out./nov./dez. 2005.

. Hierarquia Constitucional dos Tratados Internacionais de Direitos Humanos e EC 45 - tese em favor da incidência do tempus regit actum. 2006a. Disponível em: <www.conpedi.org/manaus/arquivos/Anais/Paulo\%20 Ricardo\%20Schier.pdf>. p. 3.

Hierarquia dos tratados internacionais e a EC 45 - aspectos problemáticos. In: CLÉVE, Clemerson Merlin, SARLET, Ingo W.; PAGLIARINI, Alexandre Coutinho (Org.). Direitos Humanos e Democracia, Rio de Janeiro: Forense, 2006b. TEUBNER, Gunther. Die Anonyme Matrix: Zu Menschenrechtsverletzungen durch "private" transnatinale Akteure. Der Staat 45/2. Berlim: Dunker \& Humblot, p. 161-187, 2006.WOLKMER, Antonio Carlos. Pluralismo jurídico, direitos humanos e interculturalidade. Revista Seqüência, n. 53, p. 113-128, dez. 2006.

Recebido em: $14 / 3 / 2016$

Revisões requeridas em: 27/9/2016

Aceito em: 6/1/2017 